\title{
ОСОБЕННОСТИ ФУНКЦИОНИРОВАНИЯ ВЕРБАЛЬНОГО КОМПОНЕНТА В СОЦИАЛЬНЫХ КОМИКСАХ НА НЕМЕЦКОМ ЯЗЫКЕ
}

\section{FEATURES OF THE VERBAL COMPONENT IN SOCIAL COMIC STRIPS OF GERMAN LANGUAGE}

\section{Yu. Zavyalova}

Summary: The article deals with the main features of the verbal component in social comic strips of German on the material of the Internet resource http://www.respect.com.mx/de/. The development of comic plot takes place in a limited space, therefore the language of the comic strip is laconic, but it must convey various emotions of the characters. In this regard, the means used in the comic were identified at all language levels: morphological, syntactic, lexical and phonetic.

Keywords: comic strip, creolized text, verbal component, German, language means of comics.
K омикс как средство массовой коммуникации недооценивали на протяжении длительного времени. Считалось, что комиксами увлечены лишь те, кто не хочет читать настоящие книги. В настоящее время, как известно, комикс является неотъемлемой частью массовой культуры. Комиксы создаются для различных целей - рекламных, учебных, пропагандистских и просветительских. Популярность среди читательской аудитории разных возрастных групп послужила причиной возникновения многих исследовательских работ, которые посвящены теории комикса, а также анализу особенностей французских, американских, японских и корейских комиксов (К. Валеро-Гарсес, К. Вурмсхубер, Д. Грюневальд, Ю.А. Ейкалис, Л.А. Нефёдова, Д.М. Проханов, А.Г. Сонин, Л.Т. Столярова и др.).

В рамках данной статьи мы рассмотрим особенности оформления вербального компонента на всех языковых уровнях на материале социальных комиксов на немецком языке интернет-ресурса http://www.respect.com.mx/de/.

Трактовка понятия «комикс» относится к дискуссионной. Это обусловлено, возможно, тем, что структура комикса достаточно сложная, комикс-индустрия постоянно развивается, кроме этого, до середины XX века интерес к комиксу в научном мире практически отсутствовал. В конце XX века в США появляется научное исследование по теории комикса У. Айснера «Comics and Sequential Art», в котором автор называет комикс «особой организацией изображений и слов для выражения какой-либо идеи или повествования» [9, с. 5]. Далее изучение комик-
Завьялова Юлия Анатольевна

к.филол.н., старший преподаватель,

БУ ВО Ханты-Мансийского автономного округа - Югры «Сургутский государственный университет» zavyalova_yua@surgu.ru

Аннотация: В статье рассматриваются особенности оформления вербального компонента социального комикса на немецком языке на материале интернет-ресурса http://www.respect.com.mx/de/. Развитие сюжета комикса происходит в ограниченном пространстве, поэтому язык комикса лаконичен, однако должен передавать различные эмоции героев. В этой связи выявлены средства, задействованные в комиксе, на всех языковых уровнях: морфологическом, синтаксическом, лексическом, фонетическом.

Ключевые слова: комикс, креолизованный текст, вербальный компонент, немецкий язык, языковые средства комикса.

са продолжает С. Макклауд; в работах «Understanding Comics» (1993), «Вновь изобретаем комикс» (2000) им анализируется место комикса в искусстве. С. Макклауд приходит к выводу, что комикс находится на пересечении литературы, изобразительного искусства и киноискусства, сочетая в себе элементы каждого из видов искусств $[12$, с. 7$]$.

Следует отметить, что недостаточная изученность сущности комикса возникла также из-за негативного отношения у многих ученых к комиксу, так как его относили к тривиальной низкопробной литературе. К. Кайндл в своей работе «Comics in Translation» также указывает на возможные причины отсутствия четко сформулированного определения понятия «комикс»: многообразие жанров, широта целевой аудитории, множество форматов публикации [10, с. 36]. К. Кайндл предлагает рассматривать комикс как «форму повествования, которая состоит, по крайней мере, из двух изображений» [11, с. 264]. А.Г. Сонин считает, что комикс представляет собой текст, который содержит как рисунок, так и вербальное произведение; рисунок и заключённый в него вербальный текст с речью персонажей образуют органическое смысловое единство [6, с. 12]. По мнению Л.А. Нефёдовой, комиксом является «небольшая, наполненная иллюстрациями книжка, или же серия рисунков с соответствующими подписями» $[5$, с. 6].

Из выше приведенных определений следует, что комикс включает как текст, так и изображение, по этой причине комикс относят к креолизованному виду тек- 
ста. М.Б. Ворошилова отмечает, что креолизованный текст является «сложным текстовым образованием, в котором вербальные и невербальные элементы образуют одно визуальное, структурное, смысловое и функциональное целое, нацеленное на комплексное воздействие на адресата» [2, с. 181]. Л.А. Нефедова считает, что в классификации креолизованных текстов необходимо обращать внимание на то, что существует или отсутствует изображение, каким образом связано с вербальной частью: выявляются тексты с нулевой креолизацией, тексты с частичной креолизацией, тексты с полной креолизацией. В первой группе изображение не имеет значения для организации текстов. В двух других группах изображение участвует в организации текста, различаются группы тем, насколько тесно связаны вербальный и изобразительный компоненты - вербальная часть и изображение не зависят друг от друга; вербальная часть и изображение взаимосвязаны, изображение является обязательной составляющей в организации текста [5, с. 5]. Согласно представленной классификации, комиксу свойственна полная креолизация. Р. Барт, анализируя комикс как креолизованный текст, выделяет некоторые его особенности:

1. наличие жизненно-мировоззренческого конфликта между различными персонажами;

2. каждый рисунок комикса существует только в контексте всего произведения;

3. лаконичность рисунка и текстов;

4. динамичность комикса связана с его типологией;

5. броскость кадра или текста как средство привлечения внимания;

6. экспрессивность каждого кадра комикса в отдельности или всего стиля рисунка (необходимо отметить взаимосвязь яркости, лаконичности и экспрессивности);

7. раскадрованность, выделение главного в отдельные рисунки [1, с. 235].

Так как комикс состоит из вербального и невербального компонентов, лингвистам интересен вопрос функционирования данных элементов, роли каждого в комиксе. Например, Ю.А. Ейкалис исследует особенности взаимодействия вербального и невербального компонентов немецкоязычного комикса [3], Л.Т. Столярова рассматривает особенности функционирования вербального и невербального компонентов на материале комикса «Приключения галла Астерикса» Рене Госинни и Альбера Удерзо на французском языке [7].

Комикс можно назвать постоянно развивающимся явлением, так как с течением времени появляются новые форматы комикса. На структуру комикса может влиять формат, жанр, замысел автора. И.Э. Клюканов, рассматривая комикс, выявляет его идеальную структуру - текстовый ряд, который сопровождает изображение и представляет собой речь персонажа, заключённую в филактер, или комментарий автора [4, с. 18]. Однако авторы постоянно ищут новые возможности сделать комикс более привлекательным для читателей, поэтому реже используют классическую структуру комикса, в результате этого современные комиксы становятся более яркими в структурном, визуальном и в содержательном плане.

В ходе анализа текстов комиксов интернет-ресурса http://www.respect.com.mx/de/ были выявлены особенности на морфологическом, синтаксическом, лексическом и фонетическом уровнях языка, которые будут описаны ниже.

К морфологическим особенностям текста комиксов следует отнести широкое употребление настоящего времени (Präsens) в речи героев и автора, это объясняется тем, что действие комикса связано в основном с моментом речи: Ich verstehe überhaupt nicht, wovon Sie reden ... Passen Sie auf, ich zeichne ihn auf! [13]. Из прошедших времен используется Prätertum: Es ist wahr! Er war ihr Freund, und meiner auch!; Perfekt в диалогической речи: Was? ... Aber ja! Er hat mir von dir erzählt!, при согласовании времен: Ich weiss nicht, was in mich gefahren ist... [там же]; Plusquamperfekt встречается редко: Ich hatte ihn völlig vergessen, aber als ich dich sah... [там же]. Элементы разговорного языка на морфологическом уровне создают речевой портрет героя, воспроизводят национальный колорит, например, слияние форм глагола и местоимения: Siehste, was los ist! [там же]; Haste was? (Genau wie die anderen); Wo sindse den? [там же]; выпадение гласных: Schaun wir mal! [там же] или Grad erst angekommen? [там же]

Из-за ограниченного пространства кадра, где находятся реплики персонажей, а также диалогического характера речи в комиксе можно встретить определённые синтаксические структуры, которые характеризуются простотой и компактностью. Свойственная комиксу компрессия информации достигается при помощи эллиптических предложений. Члены эллиптических предложений восстанавливаются при помощи предыдущих предложений, причем могут отсутствовать как оба главных члена предложения, так и один. В качестве примеров приведем следующие реплики героев:

1. - Du kriegst noch was ab! - Und wieso [kriege ich] eigentlich [ab]?

2. - Ich versuche quadratscher zu sein. - Aber warum [versuchst du so zu sein]?

3. - Ich kann nichts dafür [machen]! [там же]

Во втором предложении примеров 1 и 2 отсутствуют сказуемое и подлежащее, которые можно определить, опираясь на первое предложение. В примере 3 отсутствует часть сказуемого, которую также можно восстановить. Важно отметить, что эллиптические конструкции встречаются достаточно часто не только в вопроситель- 
ных и повествовательных, но и в восклицательных предложениях: Alles [ist] klar bei dir! [там же] Для передачи диалогичности в тексте комикса используются предложения, которые являются незавершенными в структурном и содержательном плане; графически могут обозначаться многоточием. Предложения такого рода могут передавать эмоции героев: Ich weiss aber nicht, ob das für euch ... [там же] В тексте комикса, презентующего устную речь героев, закономерно также частое использование разговорных элементов. Высказывания, начинающиеся с глагола, приобретают экспрессивность: Gaub ich nicht!; Brauche ich nicht! [там же]. Для комикса характерны бессубъектные предложения, которые употребляются в продолжение собственного высказывания: Ach, du ekelhafter Wallone! Warte nur! [Es] Ist doch nicht meine Schuld, dass ich Flame bin und du nicht [там же]; или собственной мысли (в комиксе при помощи изображения): [Sie] Sieht aus wie eine Terroristin aus den Nachrichten [там же]. Назывные предложения в высказываниях героев могут давать оценку внешности, характера, обстановки, поведения и тд.: Hipster!; Dumme Blondchen!; Ein Müllplanet!! [там же]

Комиксы отличаются обилием повторов слов, словосочетаний, предложений. Повторы можно встретить как в рамках одного кадра, так и всего комикса; они выполняют роль акцентуации реплик героев или слов автора. Например, полный контактный повтор имеет место при передаче напряженного состояния героя: Ich werde niemals, niemals glücklich sein [там же]. Анадиплозис как разновидность повтора также придает эмоциональность репликам героев: Warum bombardiert ihr hier? Hier ist nichts! [там же] Повтор предшествующего высказывания в начале следующего может использоваться как «мостик» для перехода от одной темы к другой, что создает определённый эмоциональный фон:

- In diesem riesigen Schutthaufen finde ich bestimmt mein Stück vom Glück!

- Glück? Du glaubst an diese Dummheit? [там же]

В эмоциональной речи могут присутствовать разнообразные виды повтора, контактный повтор придаёт большую эмоциональность речи по сравнению с дистантным повтором. Дистантный повтор выполняет также архитектоническую функцию: Die Zigeuner kommen aus dem versunkenen Königreich Atlantis, wo sie Klammern für Neptun machten. Glaub es, wenn du willst... Zigeuner waren eine indische Kriegerkaste, die man vor tausend Jahren während der Gewürzkriege aus ihrer Heimat vertrieb. Glaub es, wenn du willst [там же]. Повтор одной и той же структуры предложения создает экспрессивный эффект на контрасте известной и новой информации: Wer als erster heult, der hat verloren. Wer als erster jemanden zum Heulen bringt, der hat gewonnen [там же].

Лексика языка комиксов относится ко все стилям и к различным областям, в зависимости от сюжета и замысла автора. Отмечается экспрессивность используемой лексики, а также ее эмоционально-окрашенный характер. Так, на фоне нейтральной лексики встречаются разговорные и стилистически сниженные лексические единицы, например: Du kriegst noch was ab! (umg.); Wir sollen also so weitermachen und unsere Schnauze halten? (umg.); Ich war immer der Zappelphilipp ...(umg.); Die ganze Welt will mich verarschen (salopp); Hau ab du Penner! (salopp); Assi! (umg. abwertend); Die gehen mir so auf den Sack (derb) [там же].

В комиксе особую роль играют междометия, которые обеспечивают вербальный текст краткостью и выразительностью. Междометия выражают различные эмоции и чувства: Igitt! (отвращение); Hm! (согласие, сомнение); Huch! (отвращение, ужас); Аи! (возглас боли, испуга). Фонографические средства, которые свойственны комиксу, позволяют отразить эмоциональное напряжение героя: Das Wasser ist suuuuper!; Waaas?; Neiiiin! [там же].

Из выше сказанного следует, что комикс достаточно сложное по своей природе явление. Комиксу свойственны яркость, компактность; это обуславливает наличие вышеописанных языковых средств. Комиксы постоянно изменяются, развиваются, становясь более экспрессивными в структурном и содержательном плане. Это вне сомнения вызывает интерес к дальнейшему исследованию данного феномена.

\section{ЛИТЕРАТУРА}

1. Барт Р. Мифологии. Пер. с фр., вступит, ст., коммент. С.Н.Зенкина. М. Изд-во им. Сабашниковых, 1996. 312 с.

2. Ворошилова М.Б. Креолизованный текст: аспекты // Политическая лингвистика. 2006. Вып. 20. С. 180 - 189.

3. Ейкалис Ю.А. Вербальный и иконический компоненты современного немецкоязычного комикса: Автореферат дис. .... канд. филол. наук. Самара, 2017. 23 с.

4. Клюканов И.3. Структура и функции параграфемных элементов текста: Автореферат дис. ... канд. филол. наук. Саратов, 1983. 17 с.

5. Нефедова Л.А. Когнитивные особенности комикса как креолизованного текста // Вестник ЮУрГУ. Серия Лингвистика. Вып.10, № 1 (177), 2010. С. 4 - 9.

6. Сонин А.Г. Комикс: психолингвистический анализ. Барнаул: Изд-во Алтайского гос. ун-та, 1999. 111 с.

7. Столярова Л.Г. Вербальные и невербальные компоненты коммуникации в текстах французских комиксов: на материале комиксов серии «Астерикс»: Автореферат дис. ... канд. филол. наук. Воронеж, 2012. 24 с.

8. Duden. Deutsches Universalwörterbuch (DUW). 5., überarb. Aufl. Hrsg. von der Dudenredaktion. Mannheim/Leipzig/Wien/Zürich: Dudenverlag, 2003. 2016S.

9. Eisner W. Theory of Comics and Sequential Art. Tamarac, Florida: Poorhouse Press, 1985. 164 p. 
10. Kaindl K. Comics in Translation // Handbook of translation studies. Vol. 1 / edited by Yves Gambier, Luc van Doorslaer. Amsterdam: John Benjamins Publishing Company, 2010. pp. $36-40$.

11. Kaindl K. Thump, Whizz, Poom: A Framework for the Study of Comics under Translation // Target. 1999. vol. 11, №2. pp. 263 - 288.

12. McCloud S. Understanding comics: The Invisible Art. Northampton, MA: Kitchen Sink Press, 1993. 224 p.

13. Respect [Электронный ресурс]. - Режим доступа: http://www.respect.com.mx/de/ (дата обращения: 20.02.2021).

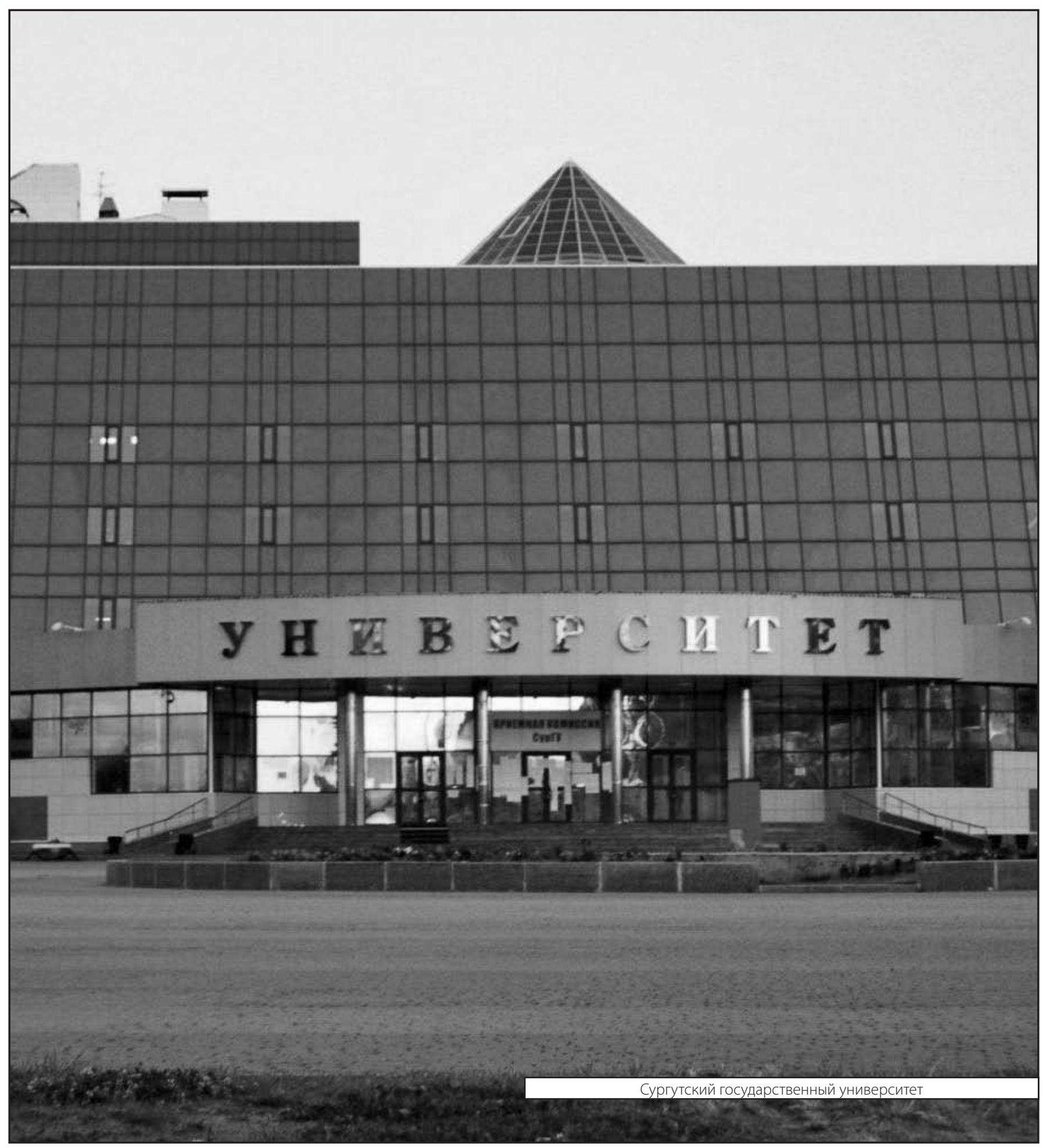

